\title{
CRESCIMENTO DE MUDAS DE CHICÓRIA ROXA “PALLA ROSSA' EM FUNÇÃO DA APLICAÇÃO FOLIAR DE ÁCIDO L-GLUTÂMICO
}

\section{PURPLE CHICORY 'PALLA ROSSA' SEEDLINGS GROWTH ACCORDING TO THE FOLIAR APPLICATION OF L-GLUTAMIC ACID}

\author{
Eliseu Geraldo dos Santos FABBRIN ${ }^{1}$ \\ Átila Francisco MÓGOR ${ }^{2}$ \\ Gislâine MARGOTI ${ }^{3}$ \\ João Guilherme FOWLER ${ }^{3}$ \\ Marcelle Michelotti BETTONI ${ }^{1}$
}

\begin{abstract}
RESUMO
Neste trabalho o objetivo foi avaliar o crescimento de mudas de chicória roxa 'Palla Rossa' (Cichorium intybus Asteraceae) submetidas a diferentes doses do aminoácido ácido L-glutâmico (AG-30 ${ }^{\circledR}$ ). O experimento foi realizado na área de Olericultura Orgânica da Estação Experimental do Canguiri/UFPR. A semeadura foi realizada no dia 06/01/2012 em bandejas de poliestireno expandido com 200 células e mantidas em casa de vegetação. Os tratamentos foram dispostos em delineamento inteiramente casualizado com 4 repetições, e constaram de aplicação via foliar de três doses $\left(0,2 \mathrm{ml} \mathrm{L}^{-1}, 0,4 \mathrm{ml}^{-1}\right.$ $\mathrm{L}^{-1}$ e $0,8 \mathrm{ml} \mathrm{L}^{-1}$ ) do produto AG-30 (ácido L-glutâmico 30\%) e testemunha sem aplicação. As aplicações ocorreram aos $17 \mathrm{e}$ 24 dias após a semeadura (DAS). Aos 31 DAS, as mudas foram coletadas e, avaliados o número médio de folhas, a altura média da parte aérea, a área média foliar, o volume médio de raiz, a massa seca média da parte área e das raízes, bem como o teor relativo de clorofila. Verificou-se que o produto $A G-30^{\circledR}$ influenciou o crescimento de mudas de chicória roxa 'Palla Rossa', com destaque para a concentração $0,2 \mathrm{ml} \mathrm{L}^{-1}$, promovendo os maiores valores médios de volume radicular, área foliar e teor relativo de clorofila.

Palavras-chave: Cichorium intybus L.; aminoácido; agricultura orgânica; biofertilizantes.
\end{abstract}

\section{ABSTRACT}

The aim of this work was to evaluate the growth of seedlings of purple chicory 'Palla Rossa' (Cichorium intybus Asteraceae) submitted to different doses of amino acid L-glutâmico (AG-30 ${ }^{\circledR}$ ). The experiment was conducted at the Organic Vegetable Experimental Station - Canguiri/UFPR. The sowing was carried in 6th march 2012. In polystyrene trays with 200 cells and maintained in a greenhouse. The treatments were arranged in completely randomized design with four replications, and had consisted of foliar application of three doses $\left(0,2 \mathrm{ml} \mathrm{L}^{-1}, 0,4 \mathrm{ml} \mathrm{L}^{-1}\right.$ e $\left.0,8 \mathrm{ml} \mathrm{L}^{-1}\right)$ of product AG-30 (ácido L-glutâmico $30 \%$ ) and a control without application. The applications occurred the 17 th and 24 th day after sowing (DAS). At 31 DAS, the seedlings had been collected and respectively evaluated: the average leaf number, the average height of shoots, the average leaf area, the average root volume, the average dry mass of shoots and the roots and relative chlorophyll content. The overview of the findings indicate the product AG-30 ${ }^{\circledR}$ influences the growth of seedlings of purple chicory 'Palla Rossa', with prominence for concentration $0,2 \mathrm{ml} \mathrm{L}^{-1}$, the biggest average values of de root volume, leaf area and relative chlorophyll content.

Key-words: Cichorium intybus L.; aminoacid; organic agriculture; biofertilizer.

'Engenheiro (a) Agrônomo (a), Mestre em Agronomia- Departamento de Fitotecnia e Fitossanitarismo, Universidade Federal do Paraná; Curitiba-PR. E-mail: eliseufabbrin@yahoo.com.br, m2bettoni@gmail.com

²Engenheiro Agrônomo, Doutor em Agronomia, Professor Adjunto do curso de Agronomia, Departamento de Fitotecnia e Fitossanitarismo, Universidade Federal do Paraná; Curitiba-PR. E-mail: atila.mogor@ufpr.br

${ }^{3}$ Graduando (a) em Agronomia - Produção Vegetal, Departamento de Fitotecnia e Fitossanitarismo, Universidade Federal do Paraná; CuritibaPR. E-mail: gislainemargoti@gmail.com, joaozinho_fowler@hotmail.com 
FABBRIN, E. G. S. et al. Crescimento de mudas...

\section{INTRODUÇÃO}

A família botânica Asteraceae tem sua importância econômica dentro das espécies olerícolas (Filgueira, 2008) sendo mais cultivados a alface (Lactuca sativa L.), a escarola (Cichorium endívia) e a chicória ou almeirão (Cichorium intybus intybus). A chicória roxa 'Palla Rossa' (Cichorium intybus) é uma cultivar que adiciona sabor picante às saladas frescas, sendo caracterizada pela coloração vermeIho arroxeada e marcantes veios brancos de suas folhas. Em função de sua utilização, principalmente na decoração de pratos elaborados, representa uma opção para os agricultores orgânicos e convencionais por seu alto valor de mercado.

A produção de mudas de hortaliças é uma das etapas mais importantes do cultivo (Silva Junior et al., 1995), ao influenciar o estabelecimento e crescimento inicial das plantas no campo. O uso de técnicas que promovam o crescimento das mudas, especialmente do sistema radicular, são bem difundidas, como por exemplo, a aplicação foliar de fertilizantes (Vital et al., 2003).

Neste sentido, em áreas como a do presente estudo, em sistema orgânico, há a necessidade de se estabelecer padrões para o uso de produtos, entre os quais os aminoácidos, oriundos de processos fermentativos, que atendam a legislação e proporcionem ganhos aos agricultores.

O emprego de aminoácidos está se tornando uma técnica comum em diversos cultivos orgânicos, com maior ênfase para as olerícolas. $O$ ácido $L$ - glutâmico obtido através da fermentação do melaço de cana-de-açucar pela bactéria Corynebacterium glutamicum, atua nas plantas de diversas maneiras. Quando absorvido por elas, é convertido em glutamato em reação catalisada pela enzima $\alpha$ ácido glutâmico descaboxilase (DAG), tornando-se precursor de muitos processos fisiológicos (Rhodes \& Handa, 1989) podendo, portanto afetar o crescimento vegetal.

Sendo assim, o objetivo deste trabalho foi avaliar a influência de aplicações foliares de soluções com diferentes concentrações do produto AG$30^{\circledR}$ (ácido L-glutâmico 30\%) no crescimento de mudas de chicória roxa 'Palla Rossa'.

\section{MATERIAL E MÉTODOS}

$O$ experimento foi conduzido na área de Olericultura Orgânica da Estação Experimental do Canguiri-UFPR (Latitude $25^{\circ} 25^{\prime}$, Longitude $49^{\circ} 06^{\prime}$; $920 \mathrm{~m}$ de altitude) para avaliar o desenvolvimento de mudas de chicória roxa "Palla Rossa' (Cichorium intybus - Asteraceae).

A semeadura foi realizada no dia 06/01/2012 em bandejas de poliestireno expandido com 200 células, preenchidas com os substratos Pró Vaso ${ }^{\circledR}$ e Plantmax ${ }^{\circledR}$, na proporção de 1: 1,5 , respectivamente, mantidas em casa de vegetação com irrigação por micro-aspersão temporizada com intervalos de duas horas, sendo cada parcela constituída por 50 células.
Os tratamentos foram dispostos em delineamento inteiramente casualizado com 4 repetições, e constaram na aplicação de três doses $\left(0,2 \mathrm{ml} \mathrm{L}^{-1}\right.$, $0,4 \mathrm{ml} \mathrm{L}^{-1}$ e $0,8 \mathrm{ml} \mathrm{L}^{-1}$ ) do produto $\mathrm{AG}-30^{\circledR}$ (Microquímica Indústrias Químicas Ltda.) composto por $30 \%$ de ácido L-glutâmico e a testemunha sem aplicação. Para a aplicação do produto $A G-30^{\circledR}$ via foliar foi utilizado um pulverizador pressurizado com $\mathrm{CO}_{2}$ com pressão constante (45 lib pol ${ }^{-2}$ ) e volume de calda equivalente a $15 \mathrm{~L} \mathrm{ha}^{-1}$ sendo as aplicações realizadas aos 17 e 24 DAS.

Aos 31 DAS, selecionou-se cinco plantas centrais, consideradas úteis, por repetição para a avaliação das seguintes características: número médio de folhas (NMF), altura média da parte aérea (AMPA), área média foliar (AMF), volume médio de raiz (VMR), massa seca média da parte aérea (MSMPA), massa seca média de raiz (MSMR) e teor relativo de clorofila (TRC).

Para identificar a AMPA, utilizou-se uma régua graduada e a medição foi realizada a partir da inserção da primeira folha. Para a obtenção da AFM e VMR as amostras foram analisadas por meio do programa computacional WinRhizo ${ }^{\circledR}$, acoplado a um Scanner LA1600 (Regent Instruments Inc., Canadá). Para a determinação da MSMPA e MSMR, o material foi colocado em estufa com circulação de ar a $60^{\circ} \mathrm{C}$ até atingirem peso constante e posteriormente pesados na balança SHIMADZU, modelo BL3200H. Para o TRC, usou-se o clorofilômetro manual N-Tester ${ }^{\circledR}$ (Yara, 2000).

Testou-se a homogeneidade das variâncias pelo teste de Barttlet, e como todas as variâncias encontravam-se homogêneas, prosseguiu-se com a ANOVA, seguida pelo teste de Tukey ao nível de $5 \%$, quando significativa. Os dados foram processados no software estatístico Assistat 7.5.

\section{RESULTADOS E DISCUSSÃO}

Os valores médios dos parâmetros avaliados são apresentados na Tabela 1. O NMF apresentou-se próximo ao encontrado por Reghin et al. (2007) de 4,38, em mudas de chicória produzidas em bandejas de 200 células aos 30 DAS. No presente trabalho, a testemunha apresentou NMF superior ao encontrado nas plantas submetidas as doses 0,4 e $0,8 \mathrm{ml} \mathrm{L}^{-1}$ de AG-30 ${ }^{\circledR}$, indicando que o aumento da concentração promoveu a redução na emissão de folhas. Entretanto, na concentração de 0,4 e $\mathrm{ml} \mathrm{L}^{-1}$ verificou-se o incremento na AMPA em relação à testemunha, mostrando que apesar da redução no número de folhas, ocorreu o aumento da altura da parte aérea, indicando a expansão, em detrimento da emissão foliar. Os valores da AMF nas concentrações de 0,2 e $0,8 \mathrm{ml} \mathrm{L}^{-1}$, quando comparados à testemunha, também indicam a expansão foliar, concordando com Vieira (2001), que afirma que uma das funções dos biofertilizantes é o incremento no crescimento e desenvolvimento do tecido vegetal, estimulando a divisão e alongamento celular. 
TABELA 1- Número médio de folhas (NMF), altura média da parte aérea (AMPA), área média foliar (AMF), volume médio de raiz (VMR), massa seca média da parte aérea (MSMPA), massa seca média de raiz (MSMR) e teor relativo de clorofila (TRC) de mudas de chicória roxa cv. "Palla Rossa" submetidas a diferentes doses de AG-30 ${ }^{\circledR}$, aos 31 dias após a semeadura (DAS). Curitiba, 2012.

\begin{tabular}{|c|c|c|c|c|c|c|c|c|c|}
\hline \multirow{2}{*}{$\begin{array}{c}\text { Doses de } \\
\text { AG-30 }\end{array}$} & \multirow{2}{*}{$\begin{array}{c}\text { NMF } \\
\text { unidade }\end{array}$} & \multirow{2}{*}{$\begin{array}{c}\text { AMPA } \\
\mathrm{cm}\end{array}$} & \multirow{2}{*}{\multicolumn{2}{|c|}{$\begin{array}{l}\text { AMF } \\
\mathrm{cm}^{2}\end{array}$}} & \multirow{2}{*}{$\begin{array}{l}\text { VMR } \\
\mathrm{cm}^{3} \\
\end{array}$} & & MMSPA & MMSR & \multirow{2}{*}{ TRC } \\
\hline & & & & & & & \multicolumn{2}{|c|}{ g planta- ${ }^{1}$} & \\
\hline $0,0 \mathrm{ml} \mathrm{L-1}$ & 6,00 a & $6,00 \mathrm{~b}$ & 23,81 & c & 1,49 & $b$ & $0,113 b$ & 0,06 ns & 231,50 \\
\hline $0,2 \mathrm{ml} \mathrm{L-1}$ & $5,00 a b$ & $8,00 a b$ & 47,41 & a & 1,64 & $a$ & $0,145 a b$ & 0,05 & 269,50 \\
\hline 0,4 ml L-1 & $4,50 \mathrm{~b}$ & 9,10 a & 29,54 & bc & 1,28 & c & $0,145 a b$ & 0,07 & 264,00 \\
\hline $0,8 \mathrm{ml} \mathrm{L-1}$ & $4,00 \quad b$ & $8,10 a b$ & 32,09 & $b$ & 0,94 & d & $0,150 \mathrm{~b}$ & 0,06 & 259,50 \\
\hline CV\% & 7,25 & 8,84 & 6 & & 1,4 & & 6,4 & 18,05 & 0,37 \\
\hline DMS & 1,44 & 2,81 & 8,12 & & 0,08 & & 0,04 & 0,04 & 3,81 \\
\hline
\end{tabular}

Médias seguidas da mesma letra minúscula não diferem estatisticamente pelo Teste de Tukey a $5 \%$ de probabilidade. ${ }^{\mathrm{ns}}$ não significativo

Outros autores verificaram o incremento da expansão foliar de mudas, como Araújo (2003) em alface e Batista et al. (2009) em mudas de chicória lisa e escarola 'Coração Cheio', ambos com resultados atribuídos ao manejo nutricional das plantas, sendo escassos os trabalhos avaliando o efeito de aminoácidos, como o de Olinik et al. (2011a), que utilizando ácido L- glutâmico na produção de mudas de repolho, também verificaram efeito no aumento da altura das plantas.

A ação do ácido L-glutâmico em promover a expansão foliar, justifica-se ao considerar que esse aminoácido, convertido na planta a glutamato, participa dos mecanismos de absorção e aproveitamento do N (King et al., 1993).

A MSMPA, que representa o acúmulo de biomassa na parte aérea, reflete em parte os resultados de AMPA e AMF, já que a concentração 0,8 $\mathrm{ml} \mathrm{L}^{-1}$ apresentou valor superior ao da testemunha, com 0,150 e 0,113 g, respectivamente. As demais concentrações apresentaram valores absolutos superiores aos da testemunha.

Os tratamentos alteraram o VMR quando comparados entre si e com a testemunha. A concentração de $0,2 \mathrm{ml} \mathrm{L}^{-1}$ promoveu o maior volume, enquanto os demais apresentaram valores inferiores ao da testemunha, com maior redução em função do aumento da concentração. Esse efeito não se refletiu na MSMR.

Segundo Menezes Júnior et al., (2000), em função do pequeno volume das células das bandejas de poliestireno expandido, pode ocorrer redução no desenvolvimento normal das mudas, especialmente do sistema radicular. Portanto, a concentração de $0,2 \mathrm{ml} \mathrm{L}^{-1}$ do produto AG-30 ${ }^{\circledR}$ mostrou-se eficiente em promover $\mathrm{o}$ crescimento radicular nas condições do experimento.

Olinik et al. (2011b), verificaram o aumento do TRC em mudas de repolho após a aplicação do AG-30 ${ }^{\circledR}$. O mesmo efeito foi observado nas mudas de chicória roxa "Palla Rossa' no presente trabalho, com os tratamentos promovendo o aumento da TCR, com destaque para a concentração de $0,2 \mathrm{ml}$ $\mathrm{L}^{-1}$. Efeito similar foi observado por Röder et al. (2011), em cultivo de beterraba no sistema orgânico.

$\mathrm{O}$ aumento do TRC indica que ocorreu a absorção e metabolização do aminoácido, uma vez que o ácido L-glutâmico participa da síntese do ácido aminolevulirico e, portanto, da síntese de clorofila (Beale et al.,1975; Taiz \& Zaiger, 2006).

\section{CONCLUSÕES}

Considerando o conjunto das características avaliadas, a concentração de $0,2 \mathrm{~mL} \mathrm{~L}^{-1}$ de AG$30 \circledR$ foi eficiente em promover ganhos no crescimento e teor relativo de clorofila de mudas de chicória roxa 'Palla Rossa'.

\section{AGRADECIMENTO}

Os autores agradecem à empresa Microquímica- Indústrias Químicas Ltda., por ceder o produto utilizado nesta pesquisa.

\section{REFERÊNCIAS}

1. ARAÚJO, W. P. Manejo da fertirrigação em mudas de alface produzidas em substrato. Campinas: 2003.70 p. Dissertação (Mestrado) - Instituto Agronômico de Campinas.

2. BATISTA, C. M. ; BISCARO, G. A. ; ROSA, R. J. M. ; RICHERS, W. P. ; MONACO, K. de A. ; SCALON, S. de P. Q . Efeito de diferentes níveis de fertirrigação nas características morfofisiológicas de mudas de chicória. Agrarian, Dourados, v. 2, p. 135-143, 2009

3. BEALE, S.; GOUGH, S. P.; GRANICK, S. Biosynthesis of delta-aminolevulinic acid from the intact carbon skeleton of glutamic acid in Greening Barley. Proceedings of the National Academy of Sciences of the United States of America, v. 72, n. 7, p. 2719-2723. 1975.

4. FILGUEIRA, F. A. R. Novo manual de olericultura. 3. ed., Viçosa: Editora UFV. 2008. 421p. 
FABBRIN, E. G. S. et al. Crescimento de mudas...

5. KING, B. J., SIDDIQI, Y., RUTH, T.J., WARNER, R. L.; GLASS, A. D. M. Feedback regulation of nitrate influx in barley roots by nitrate, nitrite, and ammonium. Plant Physiology, v.102, p.1279-1286, 1993.

6. MENEZES JÚNIOR, F. O. G.; FERNANDES, H. S.; MAUCH, C. R.; SILVA, J. B. Caracterização de diferentes substratos e seu desempenho na produção de mudas de alface em ambiente protegido. Horticultura Brasileira, Brasília, v. 18 , n. 3, p. 164-170, 2000.

7. OLINIK J. R., MÓGOR A. F., RÖDER C., FABBRIN, E. G. S., BETTONI, M. M., POLETTO, M. R. Desenvolvimento de mudas de repolho em função da aplicação foliar de ácido L-glutâmico a $30 \%$. Horticultura Brasileira, Brasília, v. 29, p. 4256-4260. 2011a.

8. OLINIK J. R., MÓGOR A. F., RÖDER C., FABBRIN, E. G. S., BETTONI, M. M. Frequência de aplicação de ácido Lglutâmico a 30\% na qualidade de mudas de repolho. Horticultura Brasileira, Brasília, v. 29, p. 4261-4264. 2011b.

9. RÉGENT INSTRUMENTS. Win/MacRHIZO V4.1c Reference. Régent Instruments Inc., Québec, Canadá. 1999. 51p.

10. REGHIN, M. Y.; OTTO, R. F.; OLINIK, J. R.; JACOBY, C. F. S Produtividade da chicória (Cichorium endivia L.) em função de tipos de bandejas e idade de transplante de mudas. Ciência e Agrotecnologia, Lavras, v.31, n. 3, p. 739747, 2007.

11. RHODES, A. S.; HANDA, S. Amino acid metabolism in relation to osmotic adjustment in plant cell. In: Cherry, J.H. (ed), Environmental stress in plants, p. 41-62. 1989.

12. RÖDER C.; MÓGOR, A. F.; BETTONI, M. M.; OLINIK, J. R.; KOYAMA, R; AMARAL, S. S. F. do. Teor relativo de clorofila em beterraba submetido à aplicação foliar de $A G 30^{\circledR}$, em sistema orgânico de produção. Horticultura Brasileira, Brasília, v. 29, p. 4130-4134, 2011.

13. SILVA JÚNIOR, A. A.; MACEDO, S. G.; SLUKER, H. Utilização de esterco de peru na produção de mudas de tomateiro. EPAGRI, 1995. 28 p. (Boletim Técnico, 73).

14. TAIZ L; ZIEGER E. Plant Physiology. Sunderland: Sinaver Associates. $3^{\text {a }}$ Ed., 2006. 722 p.

15. VIEIRA E. L. Ação de bioestimulantes na geminação de sementes, vigor das plântulas, crescimento radicular e produtividade de soja, feijoeiro e arroz. Piracicaba: 2001, 122 p. Tese (Doutorado em Fitotecnia). Escola Superior de Agricultura "Luiz de Queiroz".

16. VITAL, W. M.; TEIXEIRA, N. T.; GALLI, M. A.; LIMA, J. G. M., FERRARO, A. E.; SHIGIHARA, R.; MIGUEL, R. S. Adubação na produção de mudas de alface. Revista Ecossistema, São Paulo, v. 27, n. 1, jan-dez, p. 63-66. 2002.

17. YARA. How to use the N-Tester. 2000. Acessado em $15 \mathrm{fev}$. 2011. Online. Disponível em: http:// www.yarabrasil.com.br/fertilizer/tools_and_services/index.aspx.

Recebido em 19/03/2012 Aceito em 05/08/2013 